Primljen / Received: 13.6.2014. Ispravljen / Corrected: 25.8.2014.

Prihvaćen / Accepted: 19.9.2014.

Dostupno online / Available online: 10.10.2014.

\section{Seismic performances of the structures at variation of artificial accelerograms}

Authors:

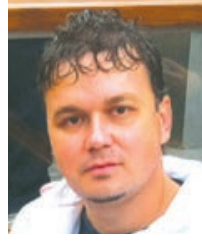

Mr.sc. Mladen Ćosić, MSc. CE (doctorand) University of Belgrade Faculty of Civil Engineering mladen.cosic@ymail.com

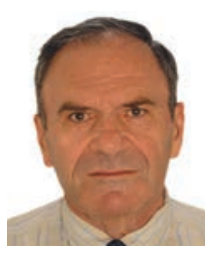

Prof. Radomir Folić, PhD. CE University of Novi Sad Faculty of Technical Sciences folic@uns.ac.rs

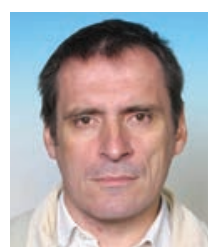

Mr.sc. Boris Folić, M.Sc. CE University of Belgrade Faculty of Mechanical Engineering Innovation Centre boris.folic@gmail.com

\section{Mladen Ćosić, Radomir Folić, Boris Folić}

Original scientific paper

\section{Seismic performances of the structures at variation of artificial accelerograms}

The impact of changes to artificial-accelerogram parameters on the seismic performance of structures is examined in this paper. The seismic response and seismic damage are analysed in this respect. Nonlinear response of the system is determined by the incremental dynamic analysis (IDA), while the damage analysis of the system is considered using the damage index. The study has shown that generation of artificial accelerograms requires a considerable number of cycles, which improves the correspondence between the range of recorded response spectra and the range of the response spectra according to EN 1998-1, which is measured based on deviation of spectral acceleration curves as a function of the ductility of the system.

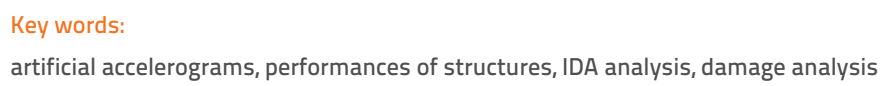

Izvorni znanstveni rad

Mladen Ćosić, Radomir Folić, Boris Folić

\section{Utjecaj parametara umjetnih akcelerograma na seizmički odziv konstrukcija}

U radu je proučen utjecaj promjene parametara umjetnih akcelerograma na seizmičke karakteristike konstrukcija. Pri tome su analizirani seizmički odziv i seizmičko oštećenje. Nelinearni odziv sustava je određivan inkrementalnom dinamičkom analizom (IDA), dok je analiza oštećenja sustava razmatrana na osnovi indeksa oštećenja. Istraživanjem je utvrđeno da je za kreiranje umjetnih akcelerograma potreban znatan broj ciklusa kojim se poboljšava usklađenost spektra odziva zapisa u odnosu na spektar odziva prema EN 1998-1, a što je mjereno na osnovi odstupanja krivulja spektralnih ubrzanja u funkciji duktilnosti sustava.

Ključne riječi:

umjetni akcelerogrami, svojstva konstrukcije, IDA analiza, analiza oštećenja

Mladen Ćosić, Radomir Folić, Boris Folić

\section{Einfluss von Parametern künstlicher Akzelerogramme auf das seismische Verhalten von Konstruktionen}

In dieser Arbeit wird der Einfluss verschiedener Parameter künstlicher Akzelerogramme auf seismische Struktureigenschaften untersucht. Dazu sind Analysen der seismischen Antwort und Schadensanalysen durchgeführt worden. Die nichtlineare Antwort des Systems ist durch inkrementelle dynamische Analysen ermittelt, während die Schadensanalyse auf der Berechnung eines Schadensindex beruht. Die Untersuchungen zeigen, dass für die Generierung künstlicher Akzelerogramme eine bedeutende Anzahl von Zyklen erforderlich ist, die zur Verbesserung der Übereinstimmung des Antwortspektrums mit dem nach EN 1998-1 führen. Entsprechende Abweichungen sind mittels von der Duktilität abhängiger Beschleunigungsspektren bemessen. 


\section{Introduction}

Engineering structures are designed for earthquake impact on the basis of appropriate regulations, while response spectra and accelerograms are introduced as input seismic effects. It should be noted that response spectra have a much wider application in practical engineering calculations, and that accelerograms are considerably less used. However, if a structure is calculated based on the nonlinear dynamic analysis (NDA), then the use of accelerograms is obligatory. The filled and processed records of natural ground motions, i.e. accelerograms of earthquakes that occurred in the past, can be obtained from several earthquake databases. The NDA analysis is used in the context of designing new buildings of particular importance, such as bridges, tall buildings, and large halls, while the IDA analysis is used for assessing performance of structures in their nonlinear behaviour, and for assessing condition of existing structures. Thus the choice between accelerograms of natural earthquakes and artificial accelerograms should be based on whether a good base of natural earthquake accelerograms is available for a given project location. If a good quality base of natural earthquake accelerograms is lacking, then the possibility of using other natural earthquake accelerograms (replacement accelerograms) should be explored, or they need to be made compatible (spectral matching) and adjusted to response spectra as prescribed in appropriate regulations. Another option is to generate artificial or synthetic accelerograms, so that their response spectra are compatible with the response spectra presented in regulations. If an adequate base of natural earthquake accelerograms is available, but their numbers are insufficient, then artificial or synthetic accelerograms can also be taken into account in order to improve the analysis of the structure's nonlinear response. The following methods are used for creating or generating appropriate artificial accelerograms:

- methods based on making changes to existing accelerograms,

- methods in the time domain: filtered white noise, Kanai-Tajimi filter, autoregressive moving average (ARMA),

- methods in the frequency domain.

The modification of existing accelerograms is based on the reduction of the accelerogram time-step through which the frequency content of the earthquake is changed. The response spectra of the modified accelerogram are now corrected, and become closer to the design (target) response spectra. Another option is to create modified response spectra from two or more response spectra, thus approaching the design response spectra both through the spectral acceleration amplitude and frequency. Methods in the time domain are based on the passage of the white noise or the accelerograms through filters, changing their amplitudes and/or frequency content. The Kanai-Tajimi filter varies the ground motion intensity over time, but the frequency content remains unchanged. In the case of natural earthquakes, changes in the frequency over time are inter alia the consequence of the passage of longitudinal, transverse, and surface waves. The most commonly used correction method in the time domain is the ARMA method, where one or more natural accelerograms are used to generate several hundreds of similar accelerations of artificial accelerograms, which are in the statistically acceptable range. Methods in the frequency domain are based on the discrete or fast Fourier transformations, and the accelerogram can be decomposed to its Fourieramplitude spectra and phase angle spectra. Using the function of random numbers for the phase angle spectra, a new accelerogram of similar frequency contents, but with different time characteristics, is generated by reconvolution. In this way, the response spectra of the generated accelerogram can be made compatible (spectral matching) in accordance with the target response spectra. Among the above methods, the most popular are the ones situated in the time and frequency domain, which are further evolving.

The ground motion, as a non-stationary process with time-varying intensity and frequency content, can be generated as:

- a nonstationary random process model based on the time and frequency modulating functions [1],

- a stochastic process model using the intensity, frequency modulation and power spectral density function [2],

- a time-varying autoregressive moving average model [3],

- a model of artificial earthquake accelerograms using neural networks [4],

- a model of wavelet transformations [5].

Artificial accelerograms generated using one of the above defined processes is widely used for analysing behaviour of structures subjected to earthquake action. The paper [6] presents the seismic response of structures as identified using the NDA analysis, where artificial accelerograms were generated using the phase difference method, which is implemented in the NCUARTEQ software for the $1 \mathrm{D}$ and 2D soil model. The paper [7] discusses the aspects of selecting compatible artificial accelerograms for the NDA analysis of reinforced concrete (RC) buildings. The artificial accelerograms were generated by modifying actual accelerograms using the discrete wavelet transformations, so that their response spectra can be compatible with the design response spectra. Procedures for scaling and creating artificial accelerograms, whose response spectra are compatible with those prescribed in regulations, are discussed in [8]. The accelerograms were generated using the SIMQKE, TARSCTHS, and RSPMatch software. The generation of artificial accelerograms using wavelet transformations, which are based on existing accelerograms, is shown in [9]. The paper [10] presents a comparative NDA analysis for natural, compatible, artificial, natural compatible, as well as artificial and natural scaled accelerograms. The study was conducted on the system with a single degree of freedom (SDOF) with different vibration periods, which takes into account hysteretic behaviour under earthquake conditions. The variability analysis of the maximum response of structures with elastoplastic behaviour, exposed to artificial accelerograms, is presented in [11]. The paper [12] uses several procedures to create compatible accelerograms for the NDA analysis of SDOF systems: unscaled accelerograms of natural earthquakes, scaled accelerograms, additionally scaled accelerograms, accelerograms corrected using the wavelet theory, 
nonstationary artificially generated accelerograms, and stationary artificially generated accelerograms.

The following procedures are applied for natural and artificial accelerograms: selection, formatting, conversion, scaling, calculation, processing, compatibilisation, normalisation, filtering, generation, and transformation. Certain procedures are mutually compatible or complementary, while others are mutually independent. On the other hand, it is not always necessary to carry out all these procedures for seismic calculations. In natural earthquake accelerograms, the selection procedure is implemented at two levels: through accelerogram bases available on the Internet, and through subsequent detailed selection based on new criteria. In artificial accelerograms, the selection process is reduced, because these accelerograms are generated based on pre-set criteria, so that it is the phase of generation in which the selection of parameters for future artificial accelerograms is also decided upon.

This paper considers the effects of varying the artificial accelerogram parameters on the seismic properties of structures defined by the IDA analysis. The study was conducted on the system with a single degree of freedom (SDOF), using the elastic response spectra specified in the EN 1998-1. The system was considered as having the elastoplastic hysteretic behaviour, taking into account that non-linear stiffness is positive and negative. The analysis focused on two groups of artificial accelerograms, each with three durations and two different stiffness values in the nonlinear domain, and with 10 artificial accelerograms for each group. For each IDA analysis, thirty nonlinear dynamic analyses were processed, with the total of 3600 NDA analyses. The seismic response and seismic damage were analysed to evaluate the system properties. Based on the analysis of results, the aim of this paper is to:

- emphasize the importance of selecting individual parameters for artificial accelerograms,

- emphasize the effects of varying parameters of artificial accelerograms,

- emphasize the effects of artificial accelerogram parameters on the seismic response of structures, and

- complement and define a detailed strategy for the generation of artificial accelerograms, in accordance with the EN 1998-1 regulations.

\section{Generation of artificial accelerograms}

The procedure of generating artificial accelerograms was conducted using the SIMQKE software [13], where the accelerogram can be expressed, in its final form, by superposition of sine functions [14]:

$a(t)=I(t) \sum_{i} A_{i} \sin \left(\omega_{i} t+\varphi_{i}\right)$

where $I(t)$ is the amplitude envelope of the generated accelerogram, $A_{i}$ is the amplitude, $\omega_{i}$ is the angular frequency, and $\phi_{i}$ is the phase angle of the $i$-th sinusoid, which is generated by the random number function in the 0 to $2 \pi$ range, with uniformly distributed probabilities. The amplitude $A_{i}$ is correlated with the power spectral density function $G(\omega)$, which is in turn correlated with the spectral acceleration as defined according to the design response spectra. This is a very convenient procedure for creating accelerograms, given that a representative accelerogram can be created for the design response spectra. Also, the accelerogram created in this way is scaled, and is compatible with the given design response spectra. Artificial accelerograms generated using the previously described procedure are stationary in time in terms of their frequency content, and nonstationary in terms of the amplitude of motion, so that they can generally be considered as being incomplete-nonstationary artificial accelerograms.

The design elastic response spectra according to EN 1998-1 (EC 8) [15] type 1, as related to type B soil, were used in the study presented in this paper. The corresponding values are: design ground acceleration $a_{g}=0.3 \mathrm{~g}$, soil coefficient $S=1.2$, damping coefficient $\xi=$ $5 \%$, and periods $T_{B}=0.15 \mathrm{~s}, T_{C}=0.5 \mathrm{~s}$, and $T_{D}=2 \mathrm{~s}$. The design elastic response spectra, and the response spectra of the generated artificial accelerograms, were defined for the period of $T_{\max }=4 \mathrm{~S}$. Artificial accelerograms of surface magnitude of $M_{s}>5.5$ can be generated by means of the design elastic response spectra specified in the EC 8. The interval of periods that should be considered when generating artificial accelerograms ranges between $0.2 T_{1}$ and $2 T_{1}$, where $T_{1}$ is the period of the structure's first mode. The entire domain of the period was taken into consideration for the purposes of this study. In order to enable better simulation and presentation of artificial accelerograms, a trapezoidal envelope was used, with the stationary domain initiation and finalization times of $t_{s, i}=2 \mathrm{~s}$ and $t_{s, f}=12 \mathrm{~s}$, respectively. According to the EC 8 recommendations, the minimum duration of the stationary part of the accelerogram should be $10 \mathrm{~s}$. The parametric analysis was performed for the entire duration of the accelerogram $t_{\text {acc }}$ and the number of cycles (iterations), which improves the level of correspondence of response spectra of the generated accelerogram $N_{i t}$ The complete duration of the accelerogram was taken to be $t_{\text {acc }}=20 \mathrm{~s}, t_{\text {acc }}=40 \mathrm{~s}$, and $t_{\text {acc }}=60 \mathrm{~s}$, while the number of cycles that improves the correspondence of the response spectra of the generated accelerograms was taken to be $N_{i t}=1$ and $N_{i t}=20$. The number $N_{i t}$ has a great influence on the generation of artificial accelerograms, given that an increase in this number considerably affects their frequency content. On the other hand, the increase in this number results in a somewhat larger number of local acceleration extremes (peaks) whose values are inclined toward the absolute value of maximum acceleration. Accelerograms were sampled at the time interval of $\Delta t=0.01 \mathrm{~s}$, and so the sampling frequency is $f_{s}=100$ $\mathrm{Hz}$. Different numbers were used to initiate generation of random numbers in order to achieve a greater difference in the accelerogram's final form. The generated artificial accelerograms were additionally processed using the baseline correction technique and filtering, with the high pass Butterworth filter passing frequencies of $f>0.2$ $\mathrm{Hz}$. The drawback of artificial accelerograms generated in this way is the possible occurrence of a large number of strong ground motion cycles and, obviously, a high amount of energy. Ten accelerograms were generated for each group, so that the total of 60 accelerograms was generated. 
The left-hand side of Figure 1 shows the response spectra of the generated artificial accelerograms for $N_{i t}=1$, the design elastic response spectra specified in the EC 8 , and the reduced design elastic response spectra specified in the EC 8 for $t_{\text {acc }}=20 \mathrm{~s}, t_{\text {acc }}=40 \mathrm{~s}$, and $t_{\text {acc }}=60 \mathrm{~s}$. The reduced design elastic response spectra specified in the EC 8 are determined by multiplying spectral acceleration by $0.9\left(90 \% S_{a}\right)$. Given that the artificial accelerograms where generated in the $N_{i t}=1$ iteration, there is also a deviation in their response spectra from the design elastic response spectra specified in the EC 8. Deviation is the largest in the domain of constant acceleration, and it is also significant in the domain where velocities have a major impact, while the deviation decreases with increasing periods. The standard deviation $\sigma$ of the response spectra is shown on the righthand side of Figure 1 [16]:
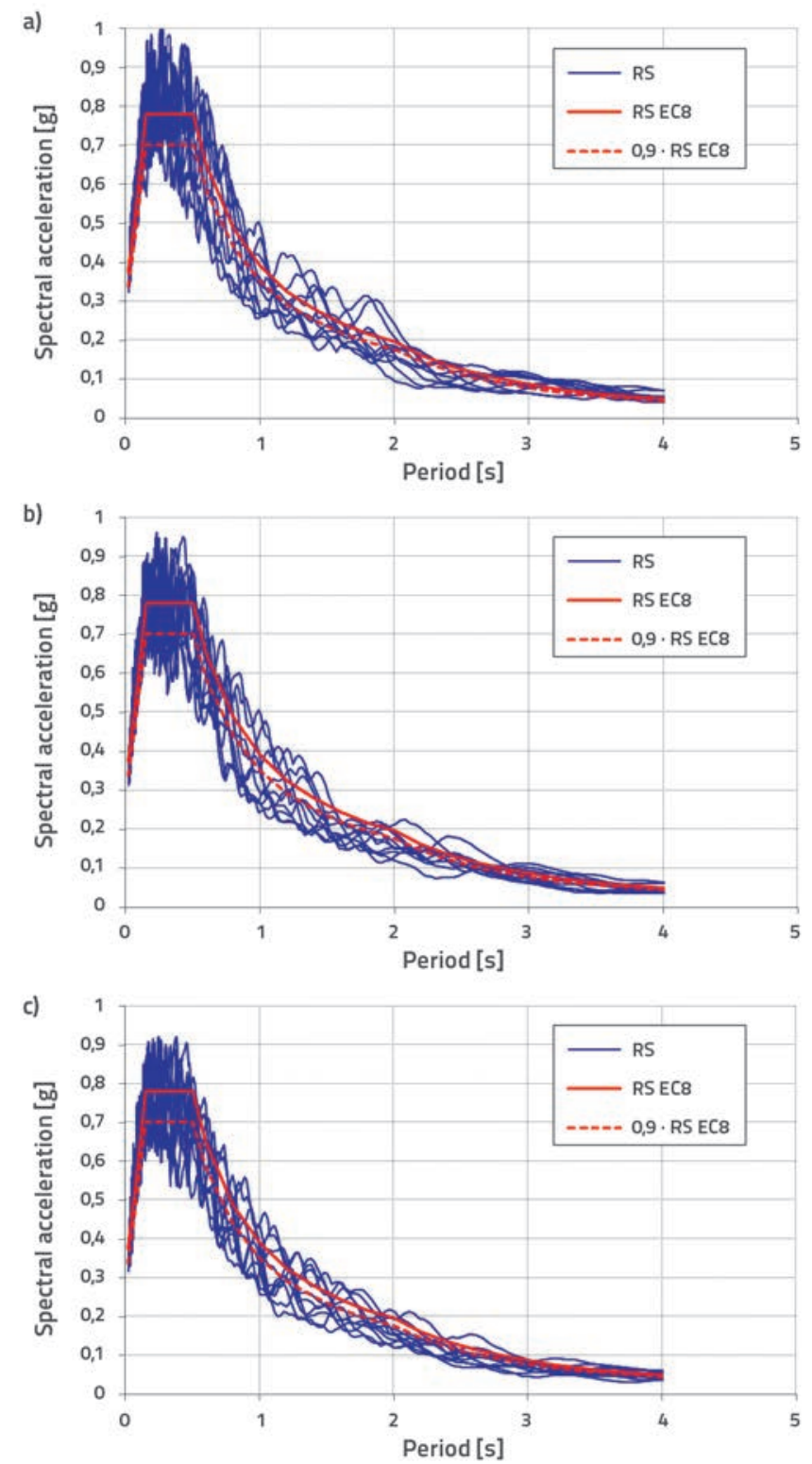

$\sigma=\sqrt{\frac{\sum\left(S_{a, i}-S_{a, m}\right)^{2}}{n-1}}$

and the variances of response spectra of the generated artificial accelerograms var:

$\operatorname{var}=\frac{\sum\left(S_{a, i}-S_{a, m}\right)^{2}}{n-1}$

where $S_{a, i}$ is the $i$-th spectral acceleration, $S_{a, m}$ is the mean value of spectral accelerations, $n$ is the total number of spectral accelerations under consideration. The above statement of deviations in spectral accelerations is confirmed by changes in standard deviation, where there is a significant deviation in the range of $0<T<2 \mathrm{~s}$, while the deviation decreases with increasing
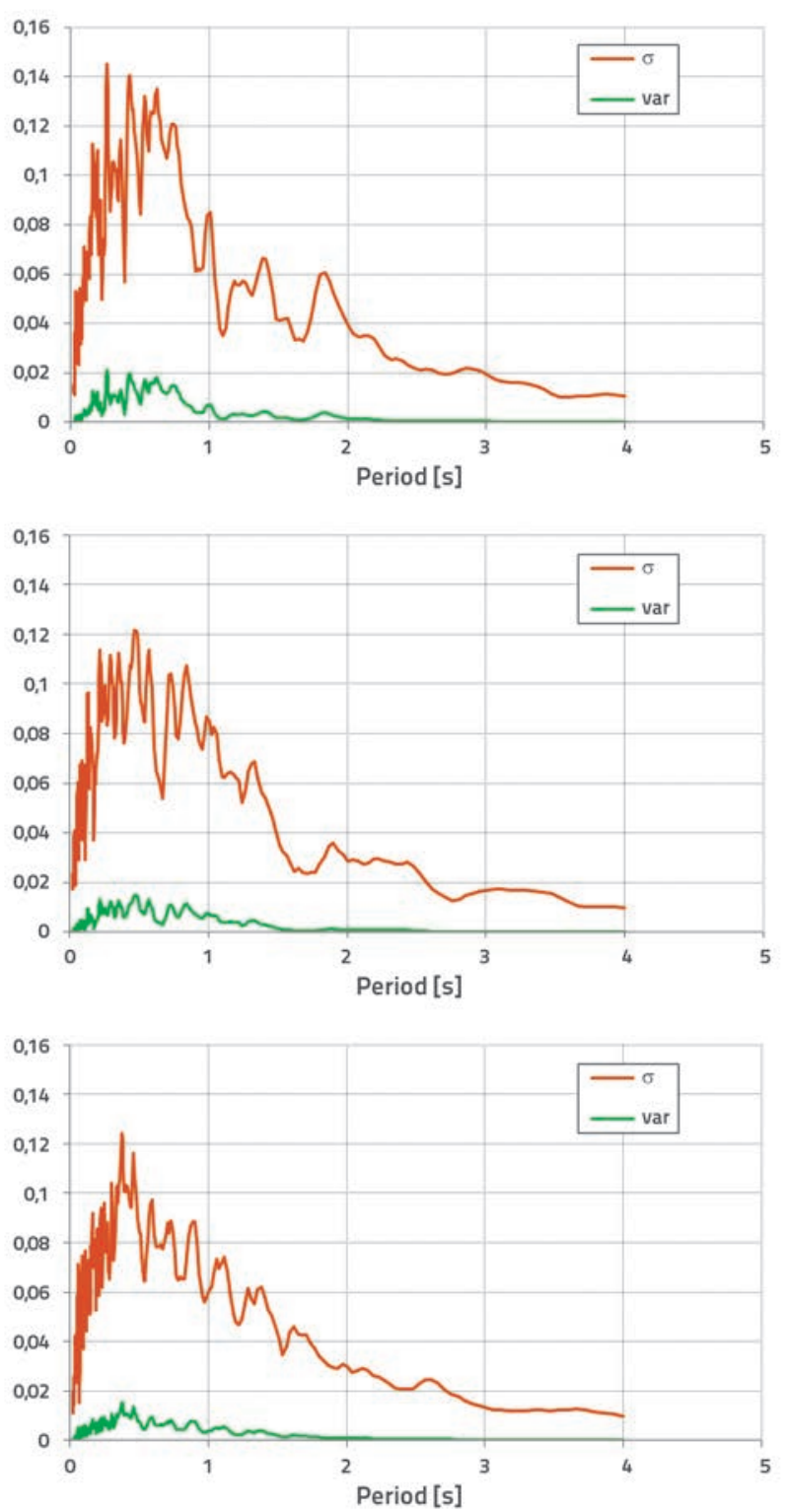

Figure 1. Response spectra of artificial accelerograms generated for $N_{i t}=1$, design elastic response spectra specified in EC 8 , reduced design elastic response spectra specified in EC 8, corresponding standard deviation $\sigma$, and variances var: a) $\left.\left.t_{\text {acc }}=20 \mathrm{~s} ; \mathrm{b}\right) t_{\text {acc }}=40 \mathrm{~s} ; \mathrm{c}\right) t_{\text {acc }}=60 \mathrm{~s}$ 

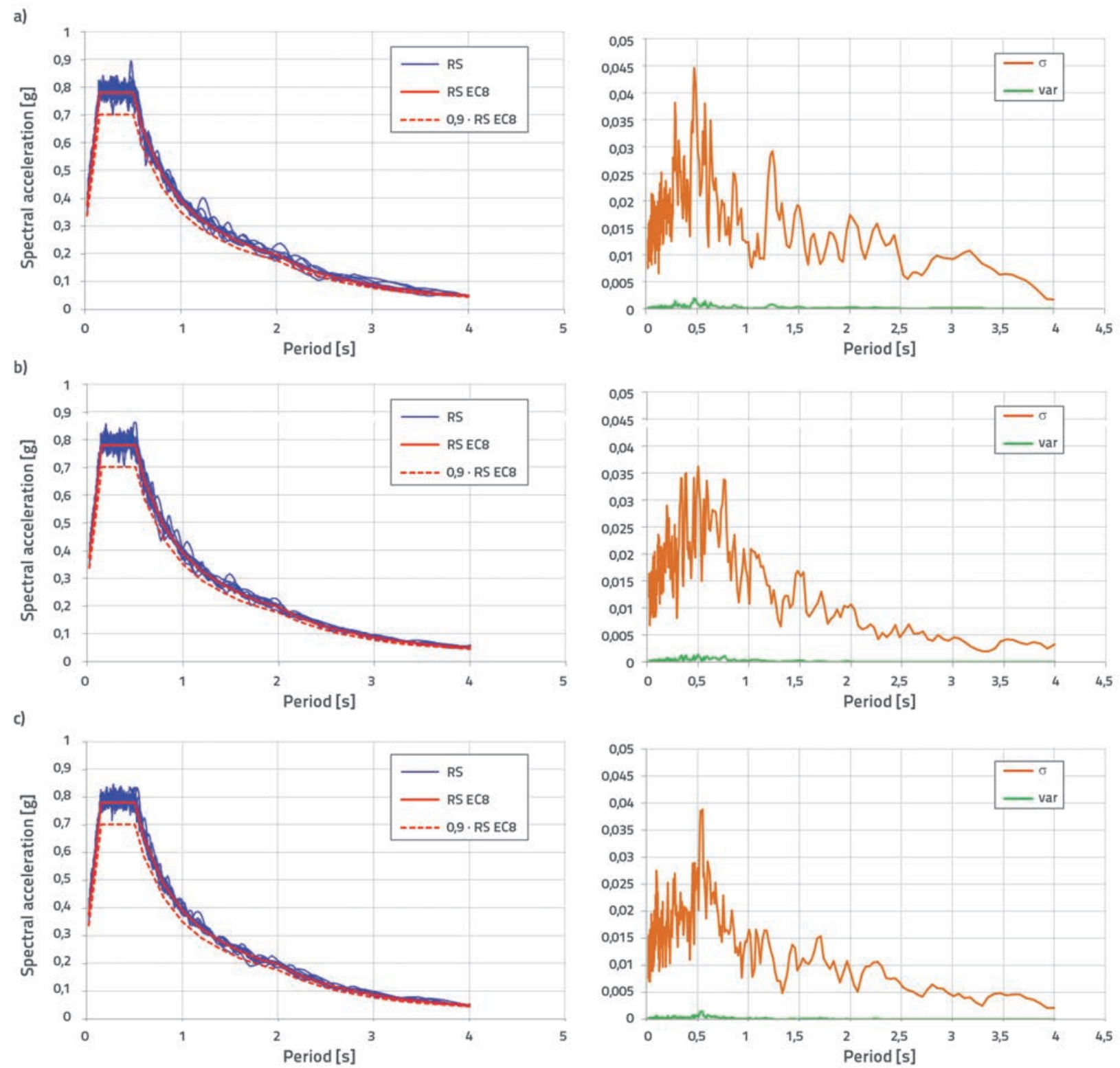

Figure 2. Response spectra of generated artificial accelerograms for $N_{i t}=20$, design elastic response spectra specified in EC 8 , reduced design elastic response spectra specified in EC 8, corresponding standard deviation $\sigma$ and variances var: a) $t_{a c c}=20 \mathrm{~s} ;$ b) $\left.t_{\text {acc }}=40 \mathrm{~s} ; \mathrm{c}\right) t_{\text {acc }}=60 \mathrm{~s}$

period by $T>2$ s. Also, the statistical parameter of variance indicates a decrease in deviation in the domain of higher periods. The left-hand side of Figure 2 shows the response spectra of artificial accelerograms generated for $N_{i t}=20$, the design elastic response spectra specified in the $\mathrm{EC} 8$, and the reduced design elastic response spectra specified in the EC 8 for $t_{\text {acc }}=20$ $\mathrm{s}, t_{\text {acc }}=40 \mathrm{~s}$, and $t_{\text {acc }}=60 \mathrm{~s}$, while the right-hand side of Figure 2 shows standard deviations, $\sigma$, and variances, var. As the artificial accelerograms were generated in $N_{i t}=20$ iterations, there is a much better correspondence between the design EC 8 elastic response spectra and the elastic response spectra of the generated artificial accelerograms. The deviation of response spectra of the generated artificial accelerograms is the largest in the domain of constant acceleration, but now it is significantly lower than in previous cases of accelerograms generated for $N_{i t}$ $=1$. Artificial accelerograms generated in this way are compatible with the design response spectra. Compatibility was checked by reducing and increasing spectral accelerations of the design elastic response spectra by $10 \%$, and by analysing the response spectra peaks of artificial accelerograms versus this reduced and increased design elastic response spectra. The results obtained were satisfactory. The standard deviation of $N_{i t}=20$ was reduced several times as follows:

$$
\begin{array}{lll}
\sigma_{\text {Nit=1 }} / \sigma_{\text {Nit=20 }}=3.22 & & t_{\text {acc }}=20 \mathrm{~s} \\
\sigma_{\text {Nit=1 }} / \sigma_{\text {Nit=20 }}=3.33 & \text { for } & t_{\text {acc }}=40 \mathrm{~s} \\
\sigma_{\text {Nit=1 }=1} / \sigma_{\text {Nit=20 }}=3.21 & & t_{\text {acc }}=60 \mathrm{~s}
\end{array}
$$



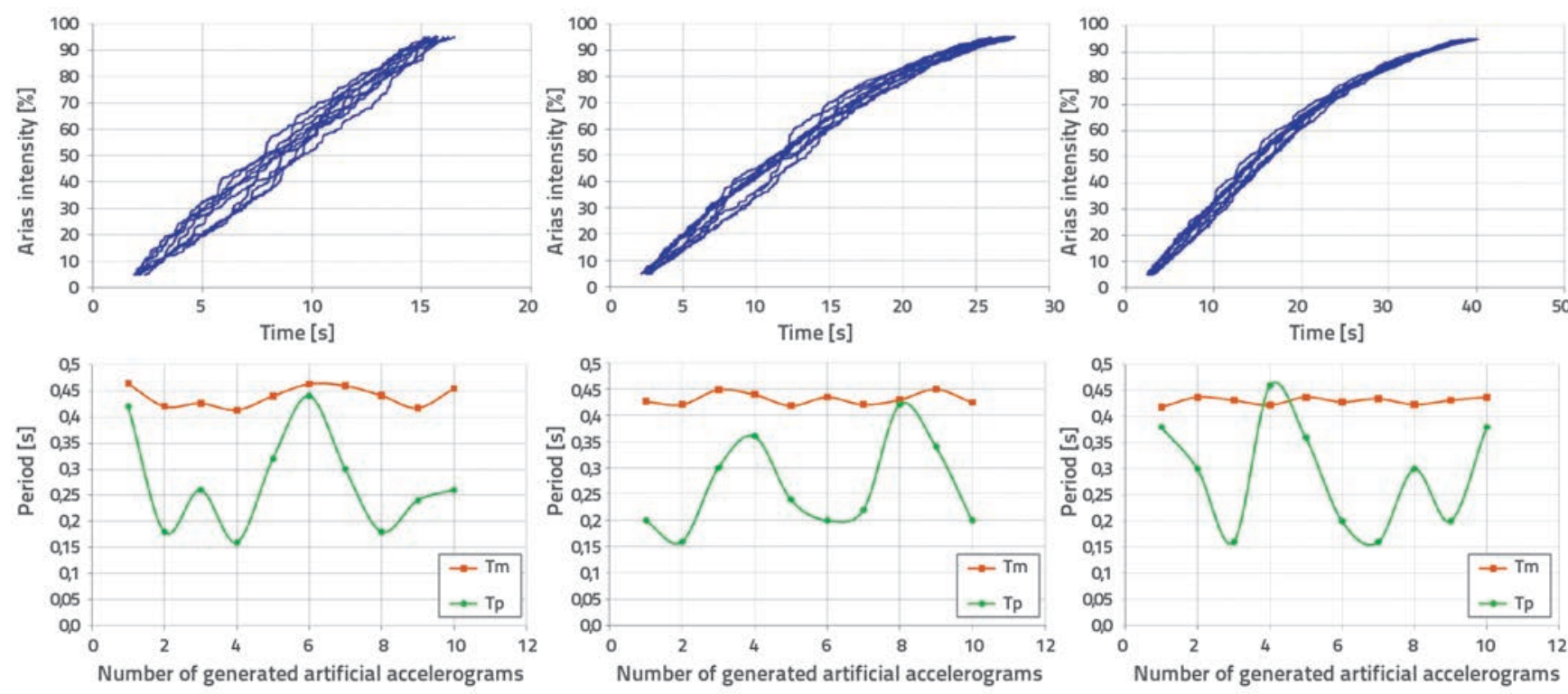

Figure 3. Charts of significant duration for Ariasintensity in the range from $5 \%$ to $95 \%$ of the time duration of the generated artificial accelerograms for $N_{i t}=1$ and the corresponding mean and predominant periods, $T_{m}$ and $T_{p}:$ a) $t_{a c c}=20 \mathrm{~s}$; b) $\left.t_{a c c}=40 \mathrm{~s} ; \mathrm{c}\right) t_{\text {acc }}=60 \mathrm{~s}$

Time diagrams of significant duration of artificial accelerograms for $N_{i t}=1$, and the corresponding mean and predominant periods, $T_{m}$ and $T_{p^{\prime}}$ for $t_{a c c}=20 \mathrm{~s}, t_{a c c}=40 \mathrm{~s}$ and $t_{a c c}=60 \mathrm{~s}$, are shown in Figure 3. The abscissa shows the values of the generated artificial accelerograms (sample) $n$. The time period of significant duration is considered for the Arias intensity [17]:

$l_{a}=\frac{\pi}{2 g} \int_{0}^{t_{\text {ace }}}[a(t)]^{2} d t$

in the range between $5 \%$ and $95 \%$ of time duration of the generated artificial accelerograms. The mean period $T_{m}$ is used for estimating the frequency content [18]:

$T_{m}=\frac{\sum C_{i}^{2} / f_{i}}{C_{i}^{2}}$

where $C_{i}$ is the Fourier amplitude, and $f_{i}$ is the frequency in the $0.25=20 \mathrm{~Hz}$ interval of discrete Fourier transformations. The predominant period $T_{p}$ is the period corresponding to the maximum spectral acceleration in the response spectra at the $5 \%$ damping level. The charts of significant duration of artificial accelerograms for $N_{i t}=20$, and the corresponding mean period $T_{m}$ and predominant period $T_{p}$ for $t_{a c c}=20 \mathrm{~s}, t_{\text {acc }}=40 \mathrm{~s}$ and $t_{\text {acc }}=$ $60 \mathrm{~s}$, are shown in Figure 4. Obvious differences can be noted when comparing significant duration of artificial accelerograms
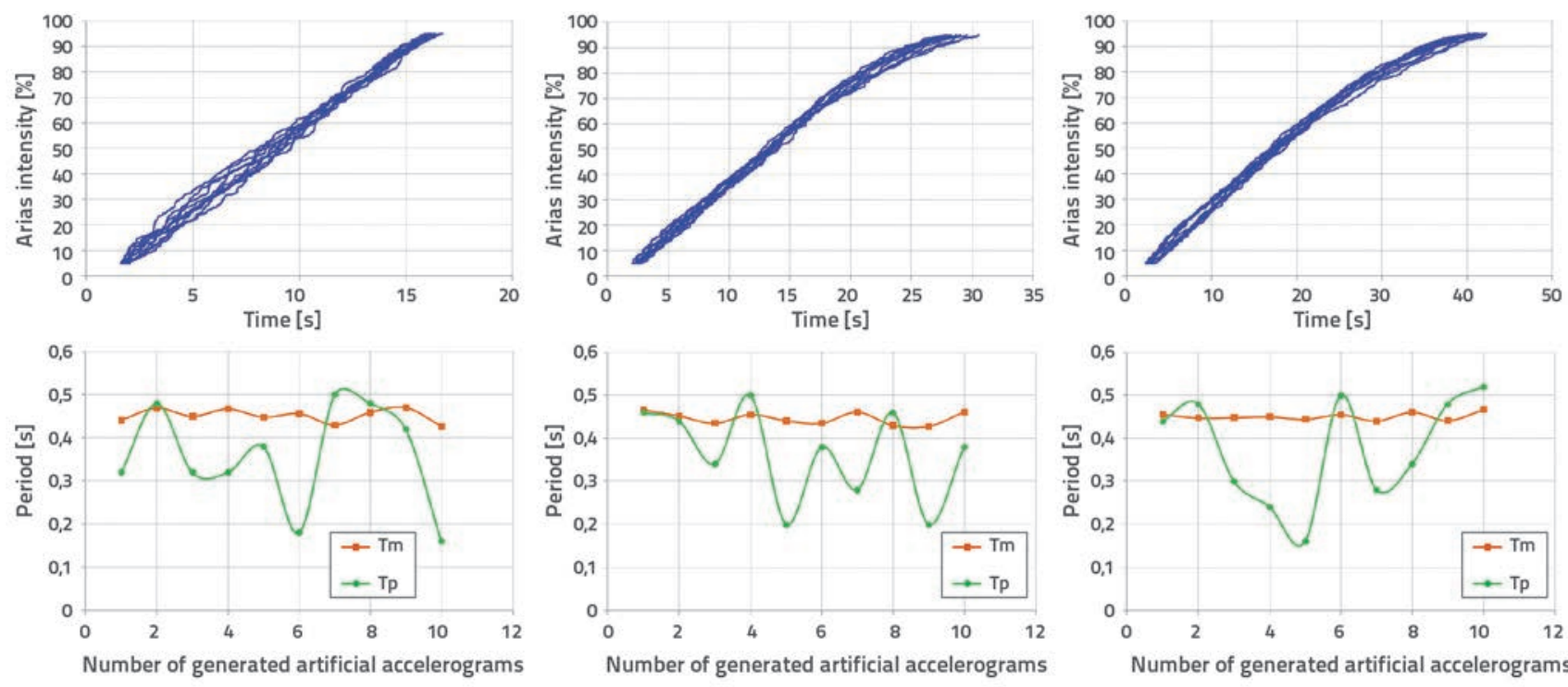

Figure 4. Charts of significant duration for Arias intensity in the range between $5 \%$ and $95 \%$ of the duration of the generated artificial accelerograms for $N_{i t}=20$, and the corresponding mean and predominant periods, $T_{m}$ and $T_{p}$ : a) $t_{\text {acc }}=20 \mathrm{~s} ;$ b) $\left.t_{\text {acc }}=40 \mathrm{~s} ; \mathrm{c}\right) t_{\text {acc }}=60 \mathrm{~s}$ 
for $N_{i t}=1$ and $N_{i t}=20$. Significant durations of $N_{i t}=20$ artificial accelerograms are longer, and their dissipation of sub values is lower. This is the direct consequence of differences in discrete values of acceleration, which were obtained by generating artificial accelerograms, and it is a significant deviation from $N_{i t}$ $=1$. Deviations are minimal with respect to mean periods $T_{m}$ in both groups of artificial accelerograms, and for a different total duration of accelerograms $t_{\text {acc }}$. Values of predominant periods $T_{p}$ for $N_{i t}=1$ are lower than the mean period $T_{m^{\prime}}$ except for one case, while $N_{i t}=20$ is accompanied by a larger number of discrete values of the predominant period $T$ that are larger than the mean period $T_{m}$ for all duration times of the generated artificial accelerograms.

\section{Analysis of seismic properties}

Properties of the bilinear elastoplastic SDOF system with the hysteretic behaviour model were considered using the seismic response analysis and seismic damage analysis. The seismic response analysis was conducted using the incremental dynamic analysis (IDA), and the system response was considered in the capacity domain.

Figure 5a shows elastoplastic models with positive $K_{n}>0\left(K_{n} / K_{e}=\right.$ $5 \%)$ and negative $K_{n}<0\left(K_{n} / K_{e}=-5 \%\right)$ non-linear stiffness, where $K_{e}$ is the elastic stiffness, while Figure $5 b$ shows the corresponding hysteretic model for $K_{n}>0$. The bilinear elastoplastic behaviour model is presented using relative coordinates, and so the ductility $\mu$ is presented on the abscissa, while the force $V$ reduced by the yielding force $V_{y}$ is presented on the ordinate. The following applies for the domain of linear elastic behaviour: $0<\mu \leq 1$ and $0<$ V/V $\leq 1$, while relations $1<\mu \leq 6$ and $V / V_{y}>0$ apply for the domain of nonlinear behaviour. The maximum available ductility value is limited to $\mu_{\text {max }}=6$, and so it is assumed that the system can develop a high class ductility (DCH). The system's period is $T=1 \mathrm{~s}$, while the mass $m$ in the system is identified based on the trivial expression for the SDOF system frequency $\omega^{2}=K_{e} / m$.

The IDA algorithm is implemented by scaling the accelerograms successively along the peak ground acceleration (PGA), and by monitoring at the same time the nonlinear structure response. The accelerograms were previously rescaled to the initial $P G A_{o}$ and

a)

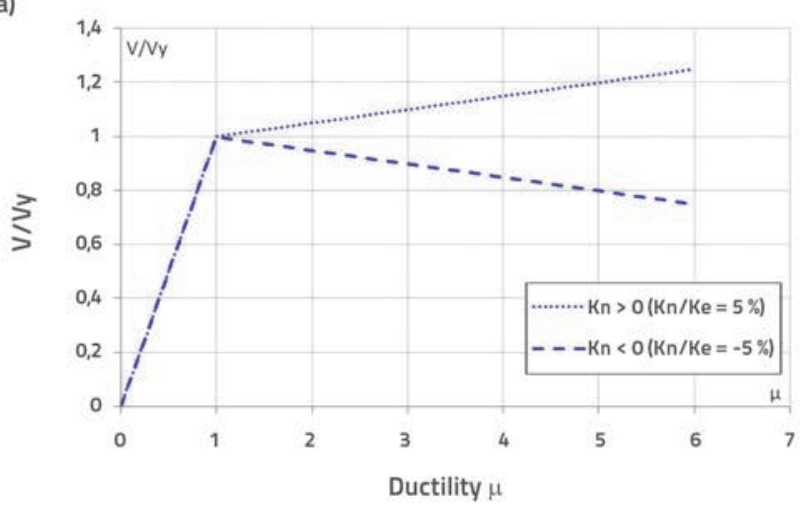

the increment of the scaling factor $\Delta F_{s}$ was determined, enabling the system to be brought to collapse condition during the IDA analysis. 30 nonlinear dynamic analyses (NDA) were processed for each individual IDA analysis. Given that two groups of artificial accelerograms ( $N_{i t}=1$ and $N_{i t}=20$ ) were taken in consideration, each with three different accelerogram durations $\left(t_{\text {acc }}=20 \mathrm{~s}, t_{\text {acc }}=\right.$ $40 \mathrm{~s}$ and $\left.t_{a c c}=60 \mathrm{~s}\right)$, two different stiffness values in the nonlinear domain $\left(K_{n}>0\right.$ and $\left.K_{n}<0\right)$, and ten artificial accelerograms, the total number of processed NDA analyses amounts to 3600 . The nonlinear response of the system is considered by varying parameters relating to artificial accelerograms, and structural parameters.

After each NDA analysis was processed at the scaling level of the artificial accelerogram $P G A$, the system response was considered through displacements in the time domain. Next, the maximum displacement $D_{\text {maxi }}$ was identified for the given $P G A$, and discretely ordered pairs $\left(D_{\text {max, }} P G A_{i}\right)$ were obtained. The system response obtained from the IDA analysis and performance analysis can be presented using various engineering demand parameters (EDP) and intensity measures (IM). It is common to present the EDP-IM ratio over $I D R_{\max }-S_{a}\left(T_{1}, 5 \%\right)$, where $I D R_{\text {max }}$ is the maximum interstorey drift, and $S_{a}\left(T_{1}, 5 \%\right)$ is the spectral acceleration for the first mode at the $5 \%$ damping level [19]. Given that this research is based on the SDOF system, the ductility $\mu$ was adopted as the EDP parameter, and $S_{a}(T, 5 \%) / S_{a, y}(T, 5 \%)$ for the IM measure, where $S_{a, y}(T, 5 \%)$ is the spectral acceleration at yield. The EDP normalization was obtained through $\mu_{i}=D_{\text {max } /} / D_{y}$, where $D_{y}$ is the displacement at yield, while the normalization for the IM has was conducted through $S_{a}(T, 5 \%) / S_{a, y}(T, 5$ $\%$ in relation to the $P G A_{i}$ Thus the spline-interpolated discretely ordered pairs $\left(\mu, S_{a}(T, 5 \%) / S_{a, y}(T, 5 \%)\right)$ were obtained, and the $S_{a} / S_{a, y}(\mu)$ IDA curve assumed its final form.

Figure 6 shows the $S_{a} / S_{a, y}(\mu)$ curves determined by IDA analysis with stiffness of $K_{n}>0\left(K_{n} / K_{e}=5 \%\right)$ for $N_{i t}=1, N_{i t}=20$ for $t_{\text {acc }}=20 \mathrm{~s}, t_{\text {acc }}=$ $40 \mathrm{~s}, t_{\text {acc }}=60 \mathrm{~s}$, while Figure 7 shows these curves determined by IDA analysis with stiffness of $K_{n}<0\left(K_{n} / K_{e}=-5 \%\right)$ for $N_{i t}=1, N_{i t}=20$ for $t_{\text {acc }}=20 \mathrm{~s}, t_{\text {acc }}=40 \mathrm{~s}, t_{\text {acc }}=60 \mathrm{~s}$. Curves, statistically determined for the mean values $S_{a} / S_{a, y}(\mu)_{m^{\prime}}$ mean values $+/$ - standard deviation $\sigma$, are also presented:

$\sigma=\sqrt{\frac{\sum\left(\left(S_{a} / S_{a, y}\right)_{i}-\left(S_{a} / S_{a, y}\right)_{m}\right)^{2}}{n-1}}$

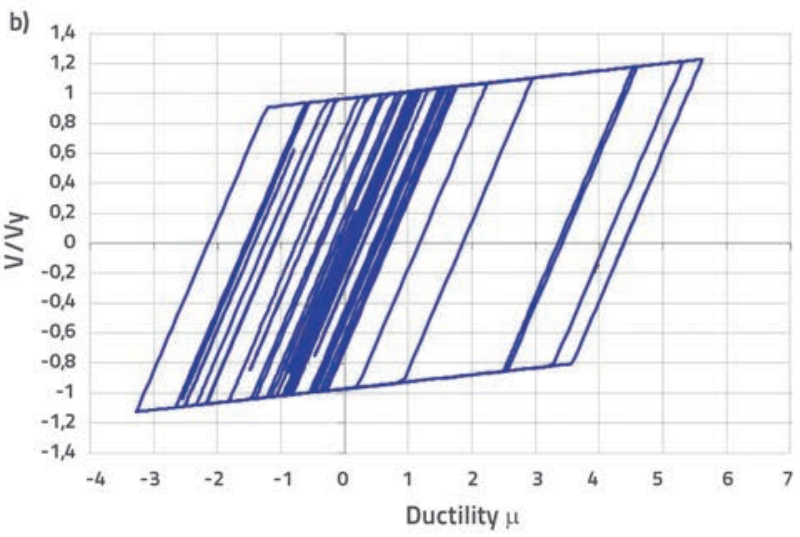

Figure 5. a) bilinear elastoplastic models with $K_{n}>0\left(K_{n} / K_{e}=5 \%\right)$ and $K_{n}<0\left(K_{n} / K_{e}=-5 \%\right)$; b) hysteretic model for $K_{n}>0$ 
where $\left(S_{a} / S_{a, y}\right)_{m}$ is the mean value and the normal distribution curve $[16] S_{a}(T, 5 \%) / S_{a, y}(T, 5 \%)$ :

$$
f\left(\left(S_{a} / S_{a, y}\right)_{i},\left(S_{a} / S_{a, y}\right)_{m}, \sigma\right)=\frac{1}{\sigma \sqrt{2 \pi}} e^{-\frac{\left(\left(S_{a} / S_{a, y}\right)_{i}\left(S_{a} / S_{a, y}\right)_{m}\right)^{2}}{2 \sigma^{2}}}
$$

The following three very different domains can be defined by analysing the $S_{a} / S_{a, y}(\mu)$ curves, which are presented with such normalized EDP-IM parameters:

- linear-elastic domain of $0<\mu \leq 1$ and $0<S_{a}(T, 5 \%) / S_{a, y}(T, 5 \%) \leq 1$,

- nonlinear domain $1<\mu \leq 6$ and $S_{a}(T, 5 \%) / S_{a, y}(T, 5 \%)>1$,

- collapse domain $\mu>6$ and $S_{a}(T, 5 \%) / S_{a, y}(T, 5 \%)>1$.

Curves in the linear-elastic domain are all perfectly straight and collinear, so that there is no deviation, because this is a consequence of the linear-elastic system behaviour. Also, due

a)

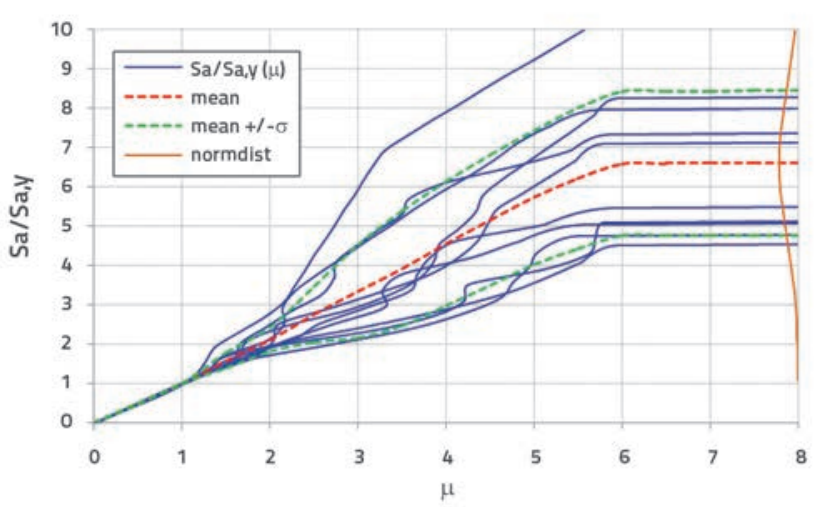

b)

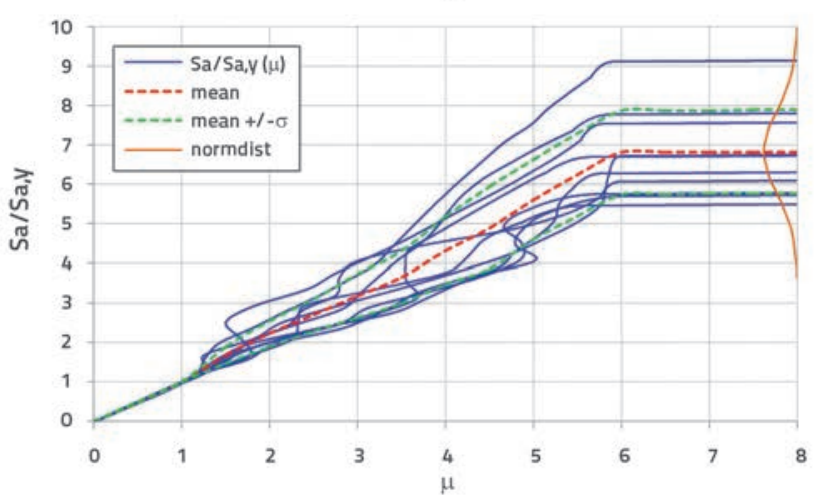

c)

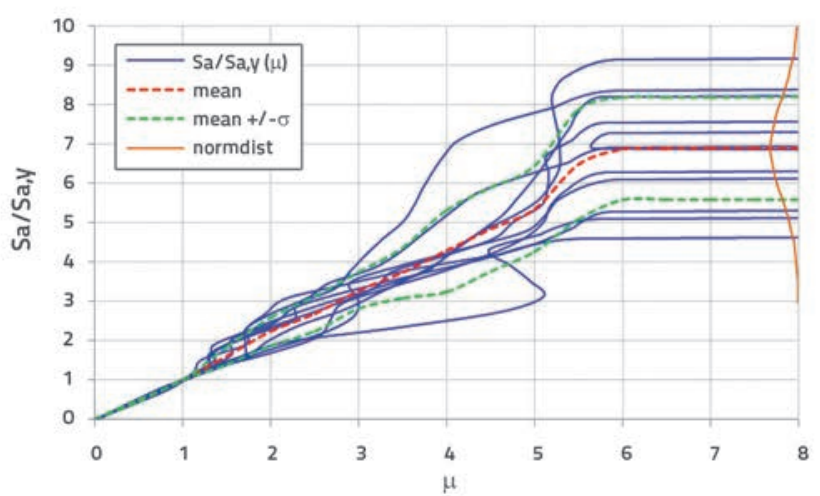

to the normalization that was performed according to the EDPIM parameters, it follows that the $S_{a} / S_{a, y}(\mu)$ curve is a straight line in this domain. In the nonlinear domain, a deviation occurs between the $S_{a} / S_{a, y}(\mu)$, which is a consequence of response of the system for generating artificial accelerograms using stochastic modulation. In the collapse domain, all $S_{a} / S_{a, y}(\mu)$ curves are asymptotically approaching the horizontal line, considering the very high displacement $D_{i}$ resulting when scaling the $i$-th accelerogram and the response system for $\mu_{i}>$ 6 within a single IDA analysis. Given that for this displacement $D_{i}$ the ductility $\mu_{i}$ is substantially higher than the maximum available ductility $\mu_{\max }=\sigma\left(\mu_{i}>\mu_{\max }\right)$, these curves are close to the horizontal line.

The developed $S_{a} / S_{a, y}(\mu)$ curves were compared through their ratio (coefficient $\Delta$ ) for $N_{i t}=20 / N_{i t}=1$ :
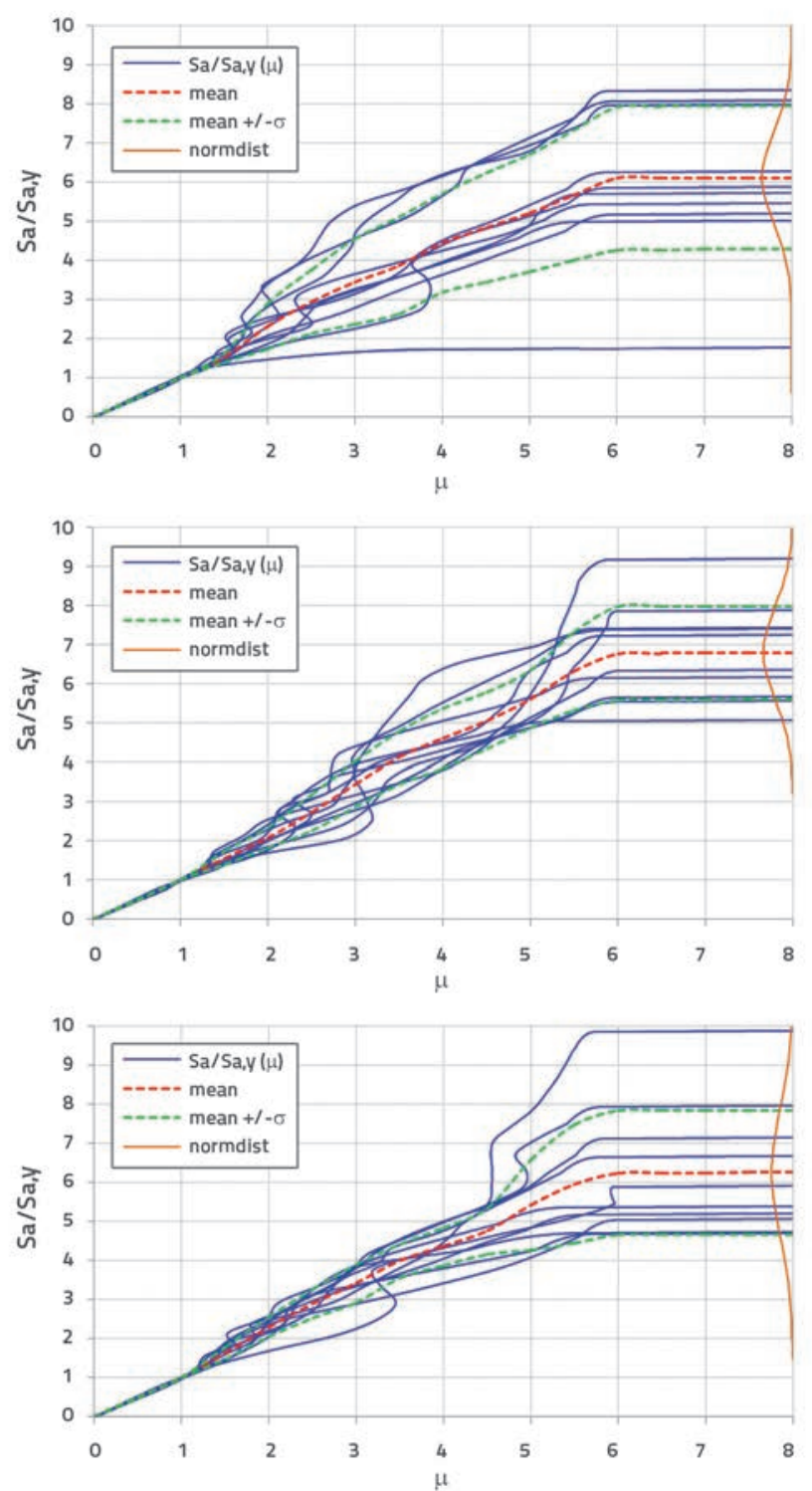

Figure 6. $S_{a} / S_{a, y}(\mu)$ curves defined by IDA analysis of the system of stiffness of $K_{n}>0\left(K_{n} / K_{e}=5 \%\right)$ for $N_{i t}=1$ and $N_{i t}=20:$ a) $t_{a c c}=20 \mathrm{~s}$; b) $t_{a c c}=40 \mathrm{~s}$; c) $t_{a c c}=60 \mathrm{~s}$ 
a)

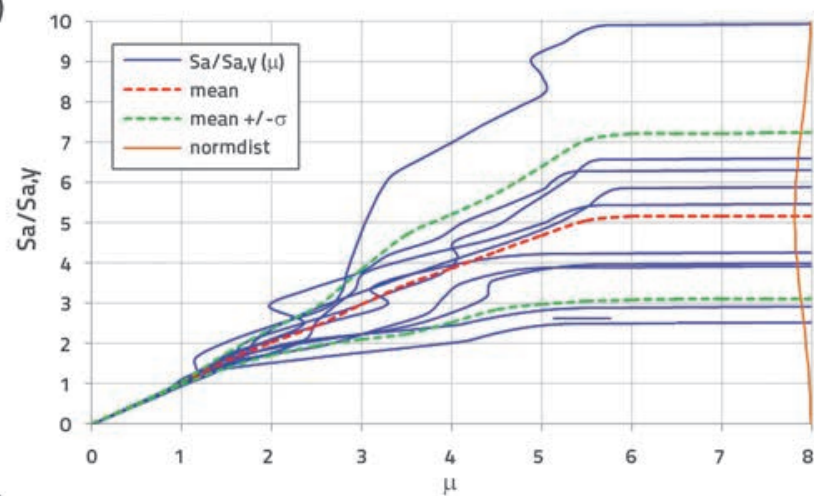

b)

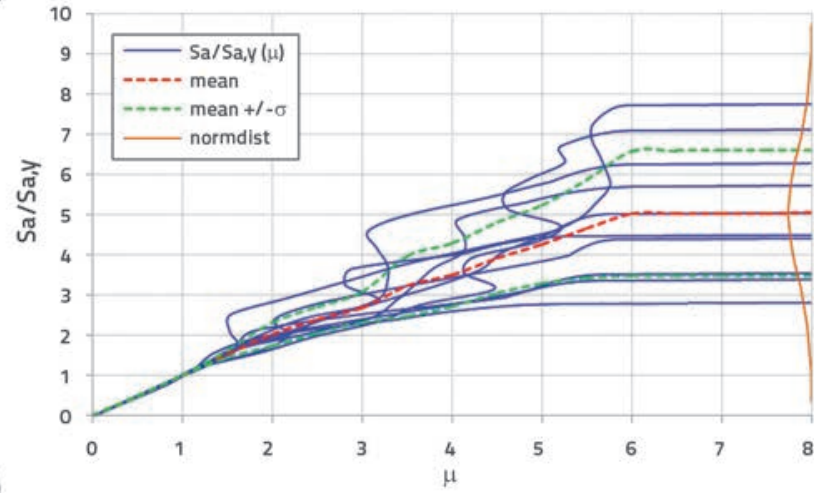

c)

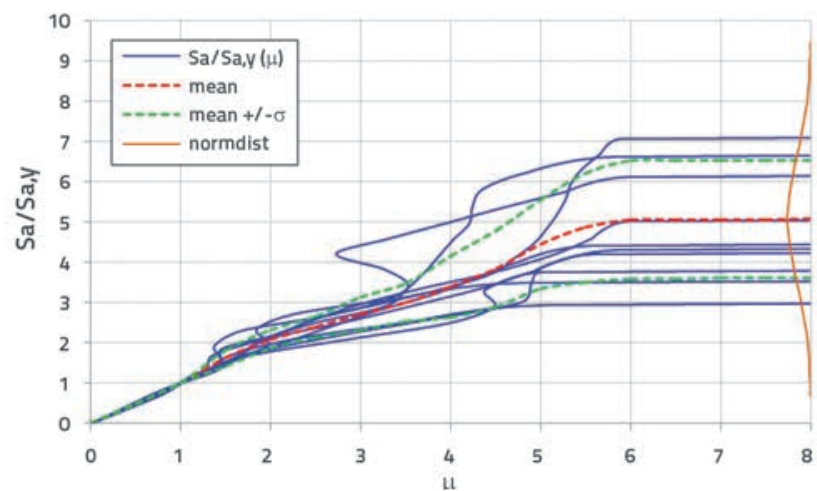

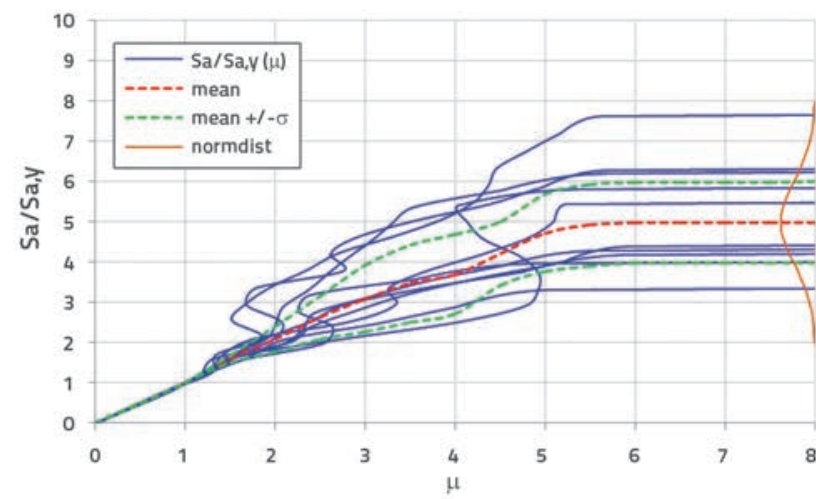
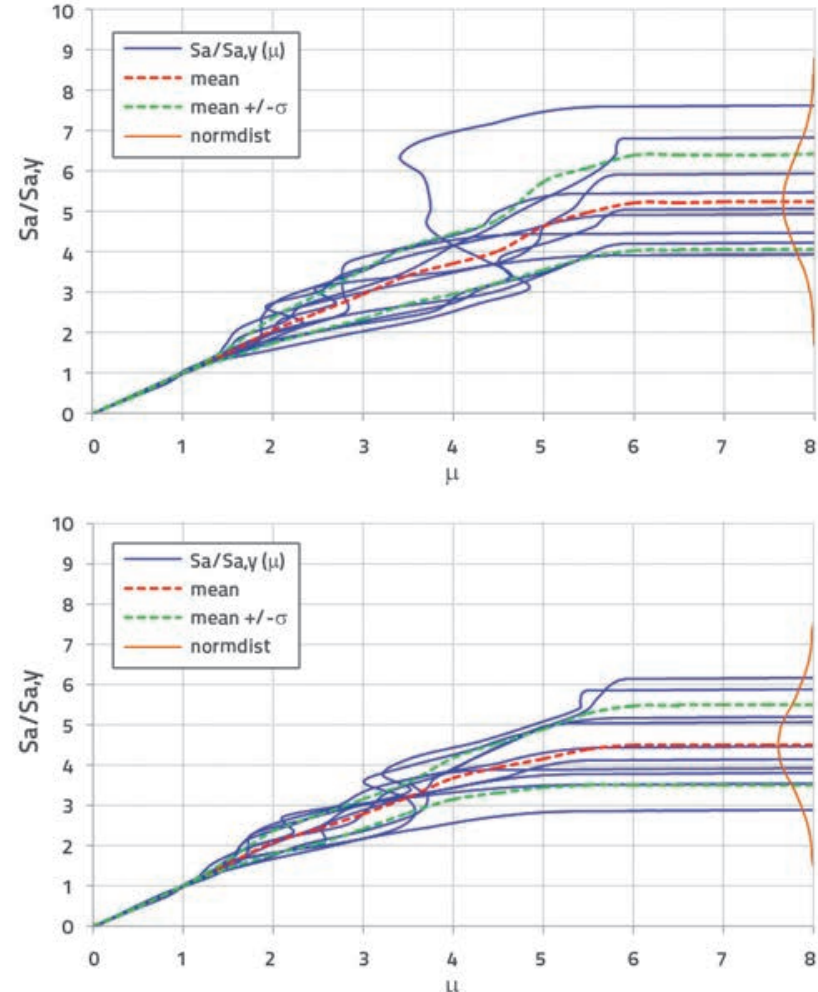

Figure 7. $S_{a} / S_{a y}(\mu)$ curves defined by IDA analysis of the system of stiffness of $K_{n}<0\left(K_{n} / K_{e}=-5 \%\right)$ for $N_{i t}=1$ and $\left.N_{i t}=20: a\right) t_{a c c}=20 \mathrm{~s} ;$ b) $t_{a c c}=40 \mathrm{~s} ;$ c) $t_{a c c}=60 \mathrm{~s}$

$$
\begin{aligned}
& \Delta=\left|\frac{\left(S_{a} / S_{a, y}\right)_{m, N i t=20}-\left(S_{a} / S_{a, y}\right)_{m, N i t=1}}{\left(S_{a} / S_{a, y}\right)_{m, N i t=20}}\right|(\%) \\
& \Delta=\left|\frac{\left(\left(S_{a} / S_{a, y}\right)_{m, N i t=20} \pm \sigma\right)-\left(\left(S_{a} / S_{a, y}\right)_{m, N i t=1} \pm \sigma\right)}{\left(S_{a} / S_{a, y}\right)_{m, N i t=20} \pm \sigma}\right|(\%)
\end{aligned}
$$

Figures 8 and 9 show the calculated $\Delta$ coefficients as a function of the varying system ductility for nonlinear stiffness values of $K_{n}>0$ and $K_{n}<0$, and for the accelerogram duration of $t_{\text {acc }}=20 \mathrm{~s}, t_{\text {acc }}=40 \mathrm{~s}$, and $t_{\text {acc }}=60 \mathrm{~s}$. The difference in the nonlinear system responses, as computed through the $\Delta$ coefficient for $N_{i t}=20 / N_{i t}=1$, amounts to as much as $20 \%$, indicating the influence of the number of a)

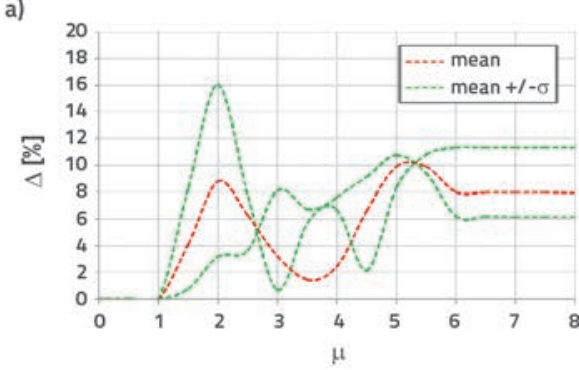

b)

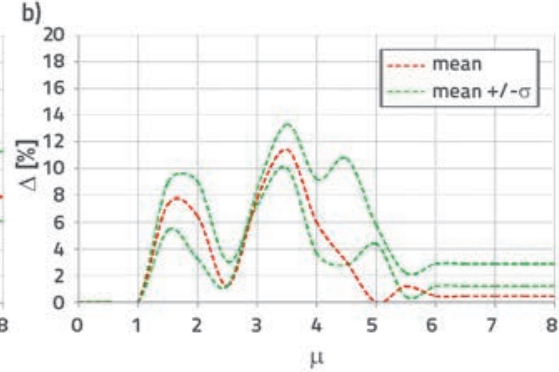

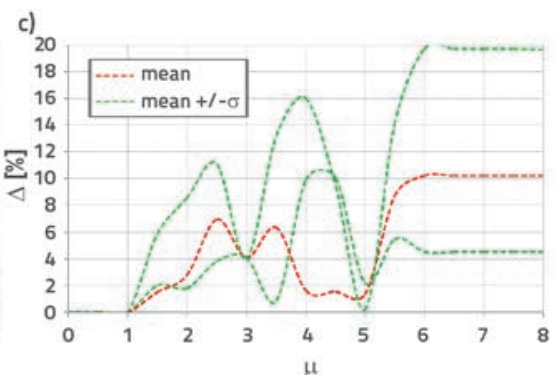

Figure 8. Charts of calculated $\Delta$ coefficients for stiffness of $K_{n}>0:$ a) $t_{a c c}=20 \mathrm{~s}$; b) $t_{a c c}=40 \mathrm{~s} ;$ c) $t_{a c c}=60 \mathrm{~s}$ 

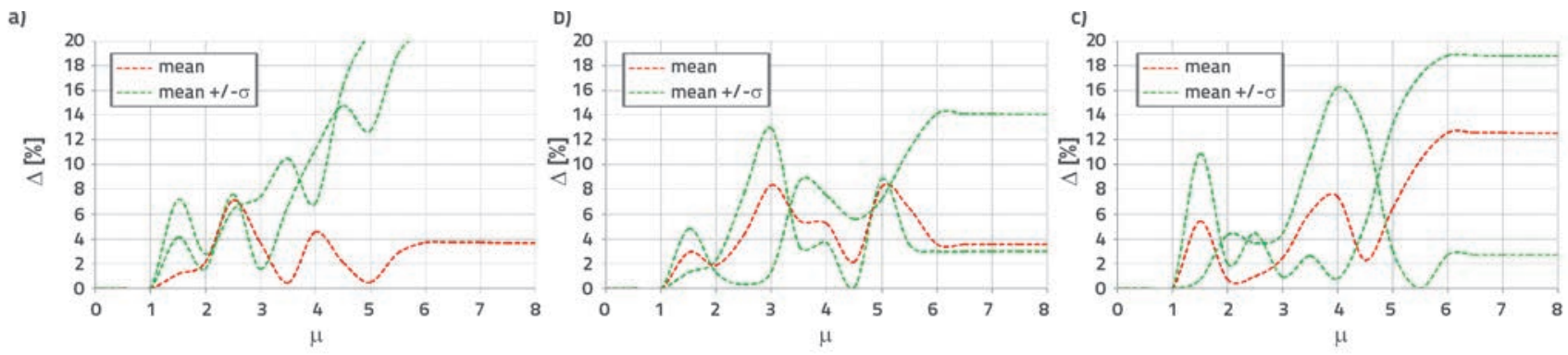

Figure 9. Charts of calculated $\Delta$ coefficients for stiffness of $k_{n}<0:$ a) $t_{a c c}=20 \mathrm{~s} ;$ b) $\left.t_{a c c}=40 \mathrm{~s} ; \mathrm{c}\right) t_{a c c}=60 \mathrm{~s}$

a)

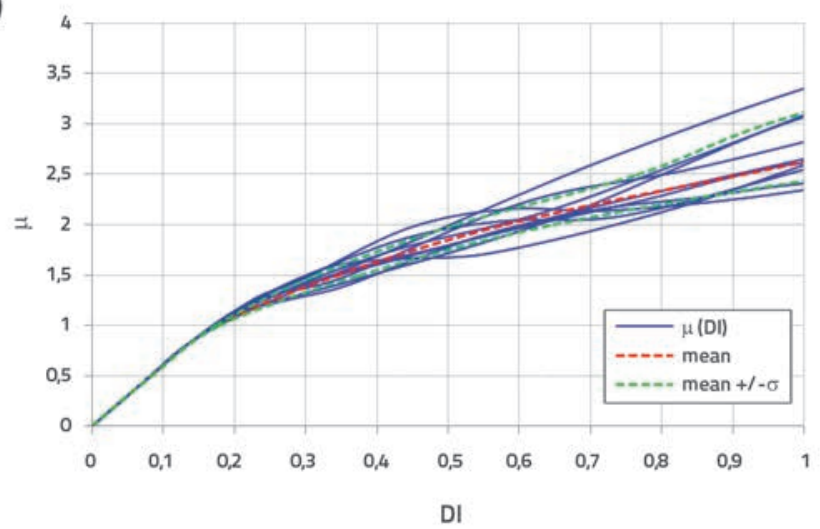

b)

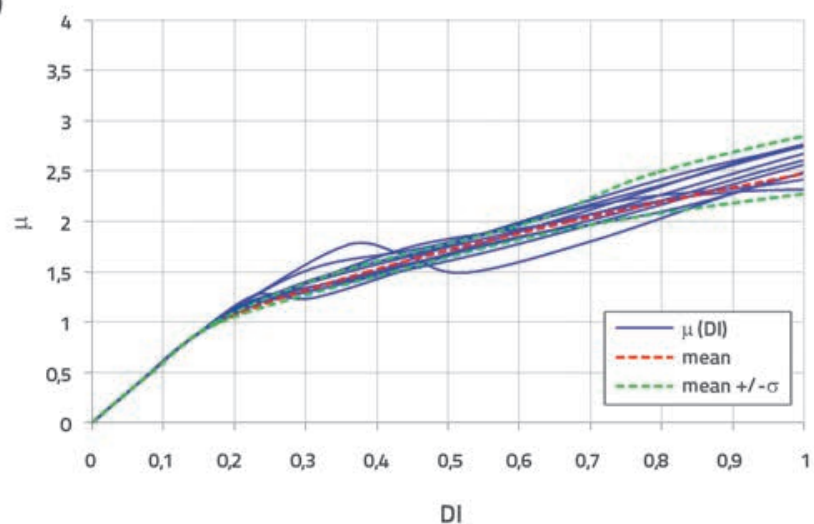

c)

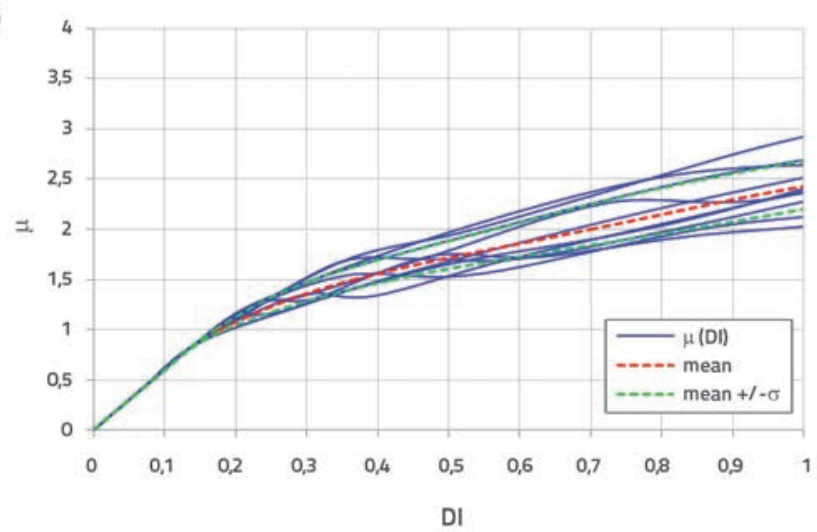

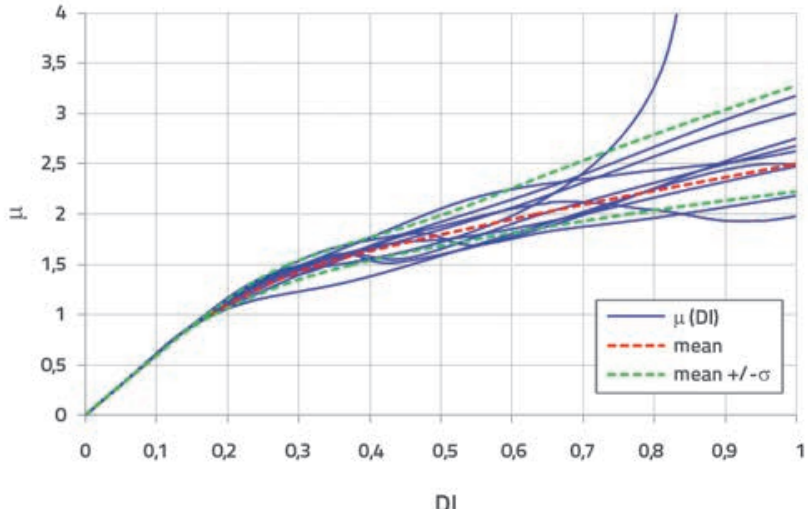
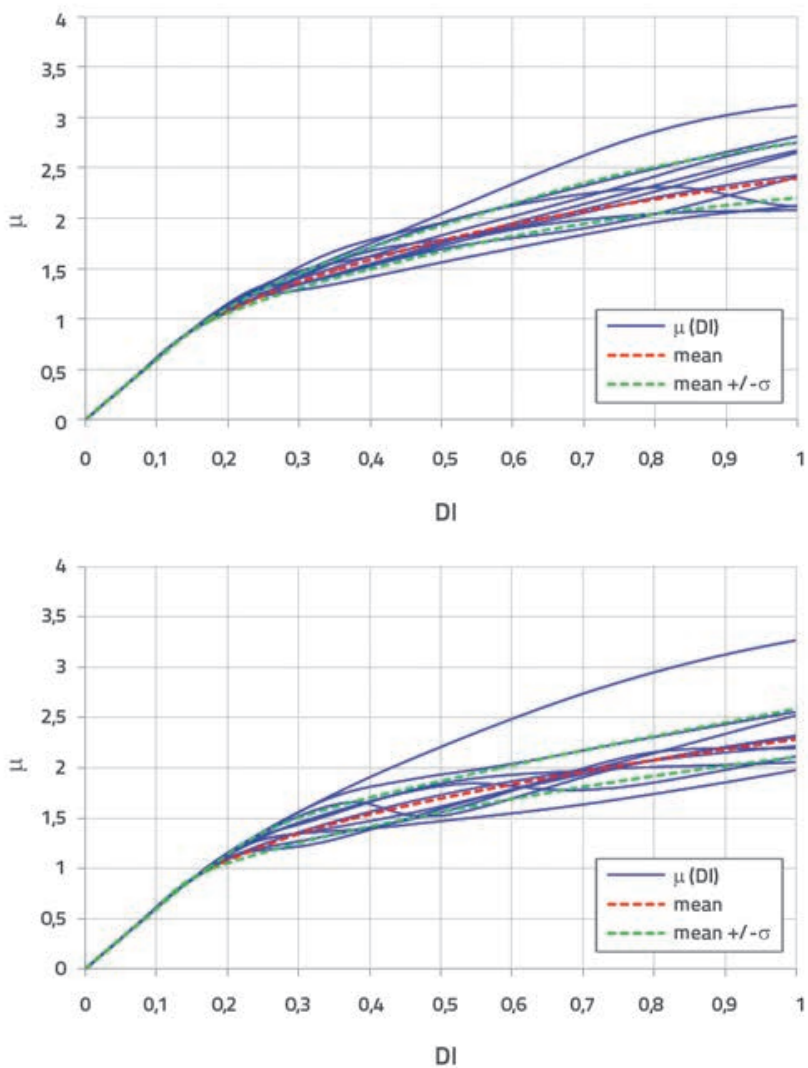

Figure 10. $\mu(D I)$ curves defined by IDA and system damage analysis with stiffness of $K_{n}>0\left(K_{n} / K_{e}=5 \%\right)$ for $N_{i t}=1$ and $N_{i t}=20$ : a) $t_{\text {acc }}=20 \mathrm{~s}$; b) $t_{\text {acc }}=40 \mathrm{~s}$; c) $t_{\text {acc }}=60 \mathrm{~s}$ 
a)

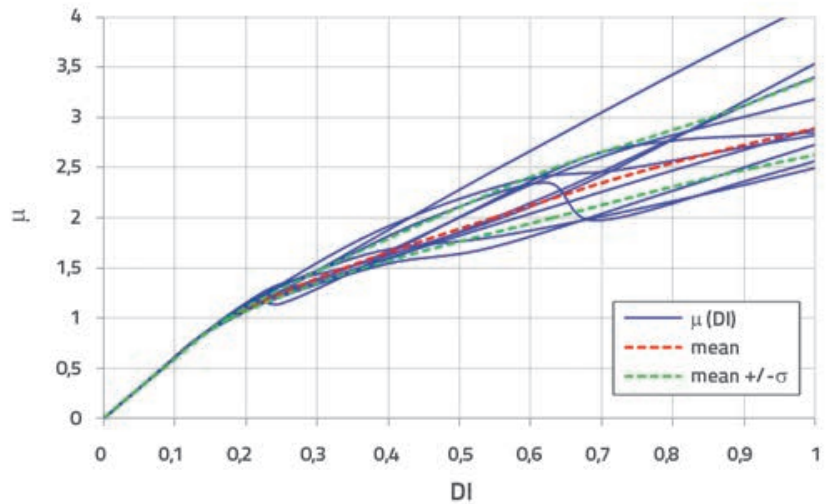

b)

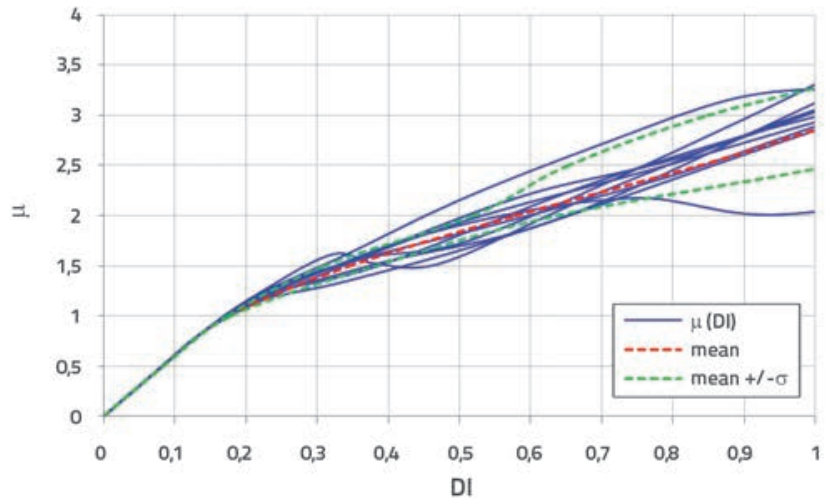

c)

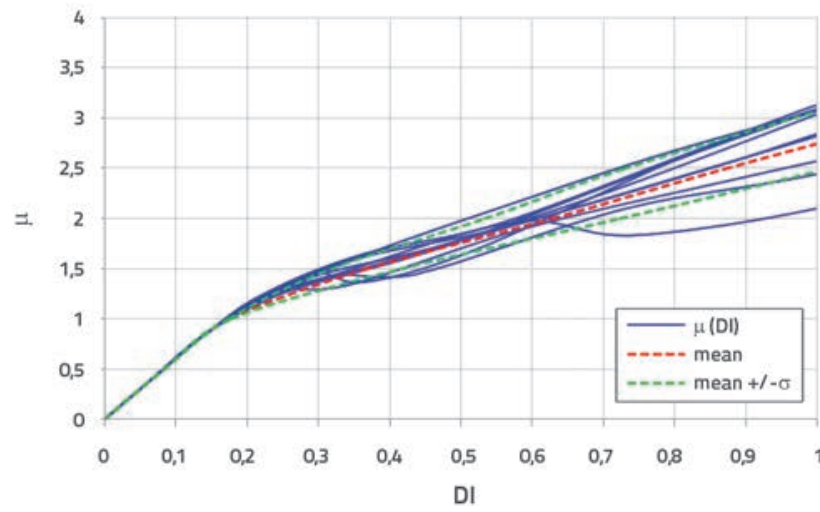

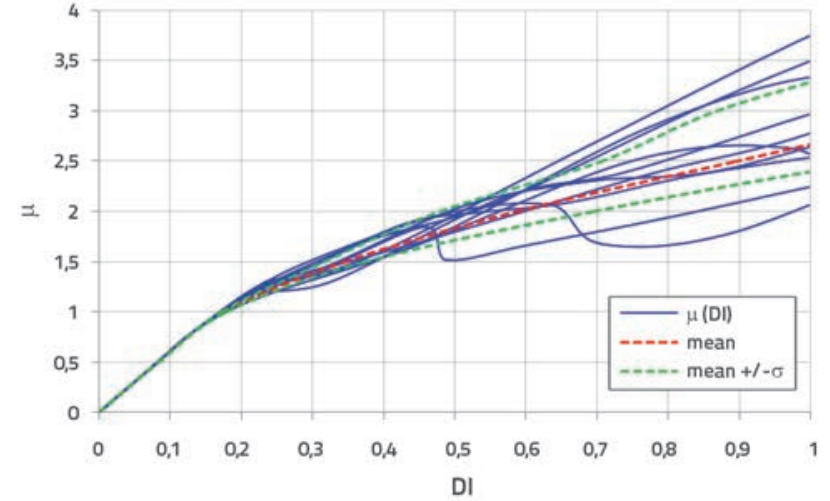
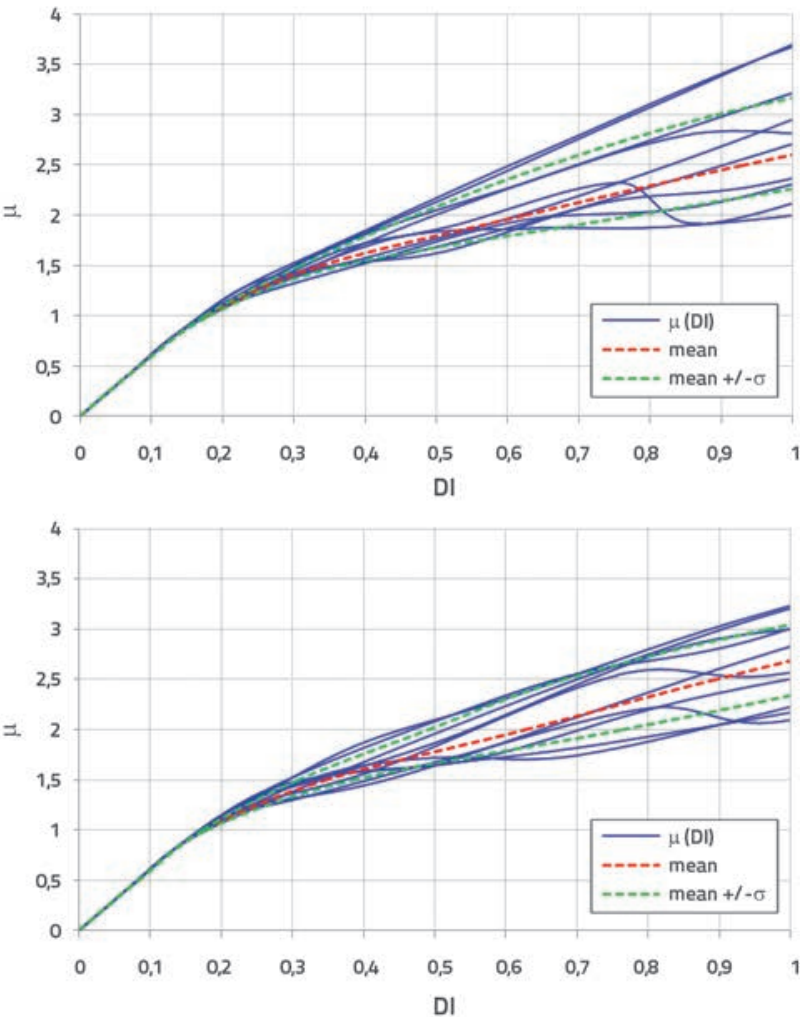

Figure 11. $\mu(D I)$ curves defined by IDA and system damage analysis with stiffness of $K_{n}<0\left(K_{n} / K_{e}=5 \%\right)$ for $N_{i t}=1$ and $N_{i t}=20$ : a) $t_{\text {acc }}=20 \mathrm{~s}$; b) $t_{\text {acc }}=40 \mathrm{~s}$; c) $t_{\text {acc }}=60 \mathrm{~s}$

iterations in generating artificial accelerograms. On the other hand, the highest deviations were obtained for artificial accelerograms with $t_{\text {acc }}=60 \mathrm{~s}$, and for the nonlinear and collapse domains.

Properties of bilinear elastoplastic systems with the hysteretic behaviour model were also considered by the seismic damage analysis based on the solution obtained using the IDA analysis. In the analysis of seismic damage, the EDP parameter was related to the damage measure (DM), where the abscissa presents the damage measure, while the EDP parameter value is presented on the ordinate. The system ductility is reserved for the EDP parameter, while the damage index $D /$ was selected for the DM measure. The damage index was determined by the NDA and IDA analysis according to [20]:
$D I=\frac{|D|_{\max }}{D_{u l t}}+\beta \frac{E_{h}}{V_{y} D_{u l t}}$

where $D_{\text {ult }}$ is the maximum capacity of the system to withstand deformation under a load with a monotonous increment (it can be assumed to be equal to $\left.4 D_{\gamma}\right), \beta$ is the coefficient depending on the system properties (0.15), and $E_{h}$ is the hysteretic energy. The level of system damage, expressed through damage index, is defined in five categories: $D /<0.1$ slight damage, $0.1 \leq D /<$ 0.25 minor damage, $0.25 \leq D /<0.4$ moderate damage, $0.4 \leq D I$ $<1$ severe damage, and $D I \geq 1$ system collapse. Figure 10 shows the $\mu(D I)$ curves determined by the IDA, and the system damage analysis with the stiffness of $K_{n}>0\left(K_{n} / K_{e}=5 \%\right)$ for $N_{i t}=1, N_{i t}=20$ 
for $t_{\text {acc }}=20 \mathrm{~s}, t_{\text {acc }}=40 \mathrm{~s}, t_{\text {acc }}=60 \mathrm{~s}$, while Figure 11 shows these curves determined by the IDA and the system damage analysis with the stiffness of $K_{n}<0\left(K_{n} / K_{e}=-5 \%\right)$ for $N_{i t}=1, N_{i t}=20$ for $t_{\text {acc }}$ $=20 \mathrm{~s}, t_{a c c}=40 \mathrm{~s}, t_{a c c}=60 \mathrm{~s}$. Curves statistically determined for the mean value $\mu(D I)_{m}$ and mean value $+/$ - standard deviation $\sigma$ are also shown:

$\sigma=\sqrt{\frac{\sum\left(\mu_{i}-\mu_{m}\right)^{2}}{n-1}}$

where $\mu_{m}$ is the mean ductility. An upper limit for the damage index, i.e. a supremum $D I_{\text {sup }}=1$, was adopted in accordance with the above defined levels of system damage based on the damage index. On the other hand, the analysis of $\mu(D /)$ curves for $D I_{\text {sup }}=1$ revealed that the ductility does not exceed the value of $\mu$ $=4$, except in two cases (two curves), so that the upper ductility limit of $\mu_{\text {sup }}=4$ was adopted. As determined by the analysis of all solutions, i.e. $\mu(D /)$ curves, the increase in the accelerogram duration ( $t_{\text {acc }}=20 \mathrm{~s}, t_{\text {acc }}=40 \mathrm{~s}, t_{\text {acc }}=60 \mathrm{~s}$ ) slightly reduces the level of ductility for the corresponding damage index value. Upper values of ductility for the damage index of $\mu(D /)$ curves are identified based on the damage level measure as follows: $D$ I $<0.1$ and $\mu<0.65,0.1 \leq D /<0.25$ and $0.65 \leq \mu<1.4,0.25 \leq D /<$ 0.4 and $1.4 \leq \mu<1.8,0.4 \leq D I<1$ and $1.8 \leq \mu<3.5, D I \geq 1$ and $\mu$ $\geq 3.5$. Based on the identified ductility of $\mu \geq 3.5$ for the damage index in the collapse condition of $D I \geq 1$, it can be concluded that the maximum available ductility of $\mu_{\max }=6$ is not reached even when the system collapse (failure) has already been registered. Compared to the previous solution, which was obtained for the collapse condition, the analysis of seismic damage provides a stricter measure for the collapse level. Given that in determining the system collapse based on the damage index the dissipation of hysteretic energy is also taken into account, different values of the corresponding system ductility can be applied for $D I=1$. The developed $\mu(D /)$ curves were compared based on their ratio ( $\triangle$ coefficient) for $N_{i t}=20 / N_{i t}=1$ :

$$
\begin{aligned}
& \Delta=\left|\frac{D I_{m, \text { Nit }=20}-D I_{m, \text { Nit=1 }}}{D I_{m, \text { Nit }=20}}\right|(\%) \\
& \Delta=\left|\frac{\left(D I_{m, N i t=20} \pm \sigma\right)-\left(D I_{m, \text { Nit=1 }} \pm \sigma\right)}{D I_{m, \text { Nit=20 }} \pm \sigma}\right|(\%)
\end{aligned}
$$

Figures 12 and 13 show the calculated $\Delta$ coefficients as a function of varying the system damage index for the nonlinear stiffness values of $K_{n}>0$ and $K_{n}<0$, and for the accelerogram duration of $t_{a c c}=20 \mathrm{~s}, t_{a c c}=40 \mathrm{~s}$ i $t_{a c c}=60 \mathrm{~s}$. The difference in nonlinear system responses computed through the $\Delta$ coefficient for $N_{i t}=20 / N_{i t}=1$ amounts to as much as $40 \%$, indicating the influence of the iteration numbers in generating artificial accelerograms.

\section{Conclusion}

The above analyses emphasize the importance of selecting individual parameters for artificial earthquakes, which are not sufficiently detailed in the EN 1998-1. When generating artificial accelerograms, the following first condition must be met: spectral acceleration values must not amount to less than $90 \%$ of spectral accelerations of the design elastic response spectra specified in the EN 1998-1. The period interval from a)

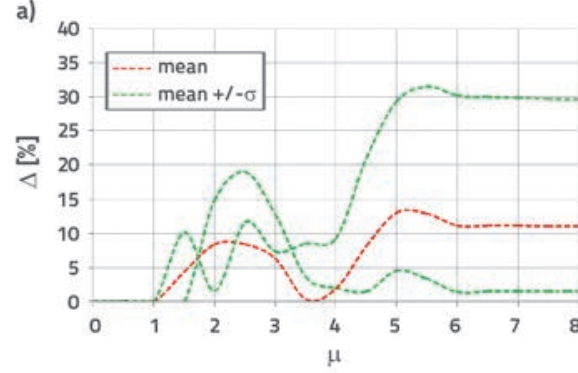

b)

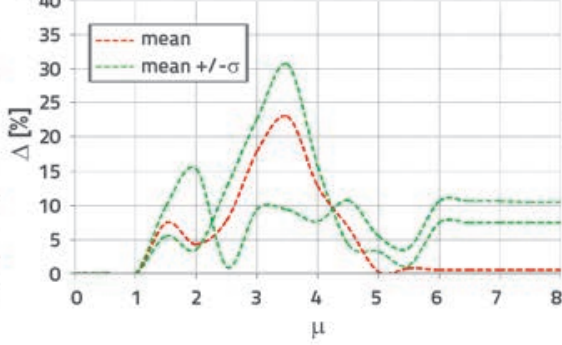

c)

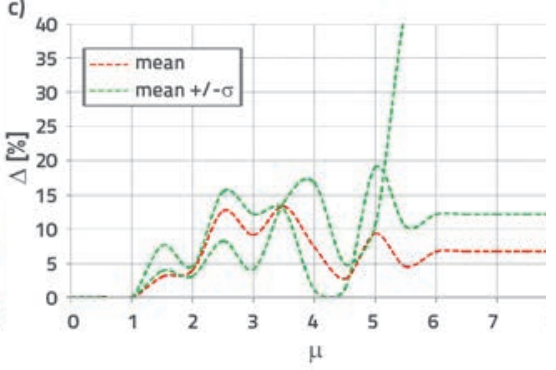

Figure 12. Charts of the calculated $\Delta$ coefficients for stiffness of $K_{n}>0:$ a) $t_{a c c}=20 \mathrm{~s} ;$ b) $\left.t_{\text {acc }}=40 \mathrm{~s} ; \mathbf{c}\right) t_{\text {acc }}=60 \mathrm{~s}$

a)

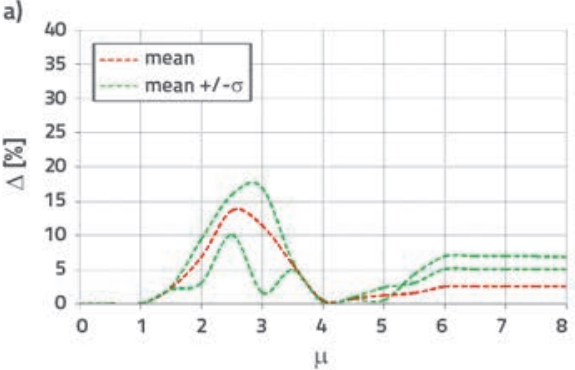

b) 40

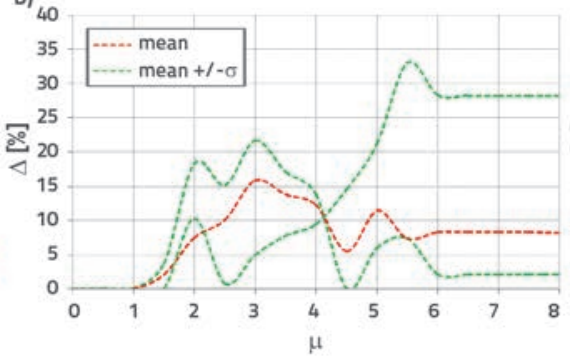

c) 40

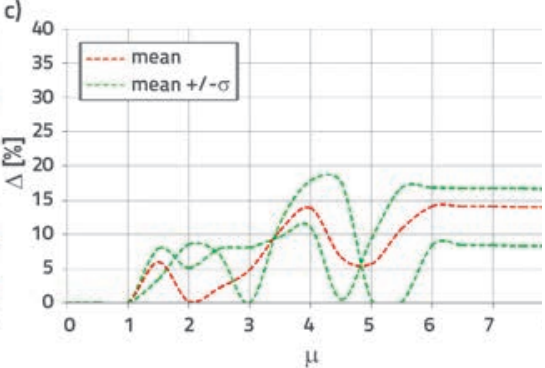

Figure 13. Charts of the calculated $\Delta$ coefficients for stiffness of $K_{n}<0:$ a) $t_{\text {acc }}=20 \mathrm{~s}$; b) $\left.t_{\text {acc }}=40 \mathrm{~s} ; \mathrm{c}\right) t_{\text {acc }}=60 \mathrm{~s}$ 
$0.2 T_{1}$ to $2 T_{1}$ for which the accelerograms are generated and scaled, requires further consideration through identification of the structure's last vibration period, in which the sum of effective modal masses for all characteristic modes exceeds 90 $\%$ of the total mass of the structure. This is the second condition that must be met, and it is particularly important to consider the lower limit of the $0.2 T_{1}$ criterion. Based on these criteria, the necessary number of cycles $N_{i t}$ required for generating the response spectra for artificial accelerograms can be identified iteratively. The research presented in this paper shows that $N_{i t}=$ 20 can meet the preset conditions.

The effects of varying artificial accelerogram parameters with regard to seismic properties of structures were studied using the seismic response and seismic damage analysis. The seismic response was investigated using the incremental dynamic analysis (IDA), while the seismic damage was analysed based on the IDA and damage index analyses. It was established that the mutual deviation of $S_{a} / S_{a, y}(\mu)$ curves, as measured by the $\Delta$ coefficient for $N_{i t}=20 / N_{i t}=1$, attains up to $20 \%$. A somewhat higher dissipation of $S_{a}(T, 5 \%) / S_{a, y}(T, 5 \%)$ values was observed for the $S_{a} / S_{a, y}(\mu)$ curves for the level of collapse condition, as measured based on normal distribution curves. This was also confirmed by higher standard deviations obtained for discrete values $S_{a}(T, 5 \%) / S_{a, y}(T, 5 \%)$ for $N_{i t}=1$ in comparison with $N_{i t}=$ 20. Based on the damage index, it was established that the mutual deviation of $\mu(D /)$ curves measured by the $\Delta$ coefficient for $N_{i t}=20 / N_{i t}=1$ attains up to $40 \%$. Also, the analysis of $\mu(D I)$ curves revealed that, as the duration of accelerograms increases ( $\left.t_{\text {acc }}=20 \mathrm{~s}, t_{\text {acc }}=40 \mathrm{~s}, t_{\text {acc }}=60 \mathrm{~s}\right)$, the level of ductility for the corresponding damage index value slightly reduces. By comparing the seismic response and seismic damage analyses, different collapse (failure) initiation levels were obtained. In the analysis of seismic damage using the damage index for $D I \geq 1$, the values obtained for the system's ductility were lower than the available maximum system ductility values. The effects of initiation of failure conditions are stronger in the systems with nonlinear stiffness $K_{n}<0$ given the substantial influence of degradation of bearing capacity in the nonlinear domain.

\section{Acknowledgments}

The work reported in this paper is a part of the investigation conducted within the research project TR 36043 supported by the Ministry for Education, Science and Technological Development, Republic of Serbia. This support is gratefully acknowledged.

\section{REFERENCES}

[1] Der Kiureghian, A., Crempien, J.: An Evolutionary Model for Earthquake Ground Motion, Structural Safety, Vol. 6, No. 2-4, pp. 235-246, 1989.

[2] Yeh, C., Wen, Y.: Modeling of Nonstationary Ground Motion and Analysis of Inelastic Structural Response, Structural Safety, Vol. 8, No. 1-4, pp. 281-298, 1990.

[3] Conte, J., Pister, K., Mahin, S.: Nonstationary ARMA Modeling of Seismic Motions, Soil Dynamics and Earthquake Engineering, Vol. 11, No. 7, pp. 411-426, 1992

[4] Ghaboussi, J., Lin, C.: New Method of Generating Spectrum Compatible Accelerograms Using Neural Networks, Earthquake Engineering and Structural Dynamics, Vol. 27, No. 4, pp. 377-396, 1998.

[5] Suarez, L., Montejo, L.: Generation of Artificial Earthquakes via the Wavelet Transform, International Journal of Solid and Structures, Vol. 42, No. 21-22, pp. 5905-5919, 2005.

[6] Chen, H-T., Ou, J-Y.: Seismic Responses of Structures Subjected to Artificial Ground Motions Generated Using 1D and 2D Ground Model, The $13^{\text {th }}$ World Conference on Earthquake Engineering, Paper No. 1765, pp. 1-9, Vancouver, Canada, 2004.

[7] Bahar, O., Taherpour, A.: Selection of Artificial Spectrum Compatible Accelerograms for Nonlinear Dynamic Analysis of RC Buildings, The $14^{\text {th }}$ World Conference on Earthquake Engineering, Paper No. 215, Beijing, China, October 12-17, 2008.

[8] Fahjan Y., Ozdemir Z.: Scaling of Earthquake Accelerograms for Non-Linear Dynamic Analyses to Match the Earthquake Design Spectra, The $14^{\text {th }}$ World Conference on Earthquake Engineering, Paper No. 165, Beijing, China, October 12-17, 2008.
[9] Nakamura, M., Sasaki, F., Yokoyama, K., Tamaoki, T., Tanabe, A., Mizumachi, W., Yamada, M.: Generation of Artificial Earthquake Motion Using Observed Earthquake Motions, The $14^{\text {th }}$ World Conference on Earthquake Engineering, Paper No. 11, pp. 1-8, Beijing, China, 2008.

[10] Laurendeau, A., Causse, M., Guéguen, P., Perrault, M., Bonilla, L., Douglas, J.: A Set of Eurocode 8-Compatible Synthetic TimeSeries as Input to Dynamic Analysis, The $15^{\text {th }}$ World Conference on Earthquake Engineering, Paper No. 4089, pp. 1-10, Lisbon, Portugal, 2012.

[11] Ichihashi, I., Sone, A., Masuda, A., Noma, T.: A Study on Variance of Maximum Responses of Elastoplastic Structure Subjected to Artificial Earthquake Ground Motions, The $15^{\text {th }}$ World Conference on Earthquake Engineering, Paper No. 976, pp. 1-10, Lisbon, Portugal, 2012.

[12] Iervolino, I., De Luca, F., Cosenza, E.: Spectral Shape-Based Assessment of SDOF Nonlinear Response to Real, Adjusted and Artificial Accelerograms, Engineering Structures, Vol. 32, No. 9, pp. 2776-2792, 2010.

[13] Simqke: URL: http://dicata.ing.unibs.it/gelfi/software/simqke

[14] Gasparini, D., Vanmarcke, E.: Simulated Earthquake Motions Compatible with Prescribed Response Spectra, Massachusetts Institute of Technology, 100p, Boston, USA, 1976.

[15] EN 1998 (Eurocode 8): Design of Structures for Earthquake Resistance - Part 1: General Rules, Seismic Actions and Rules for Buildings, European Committee for Standardization, 229p, Brussels, Belgium, 2004.

[16] Soong, T.: Fundamentals of Probability and Statistics for Engineers, John Wiley \& Sons Ltd, 408p, Chichester, USA, 2004. 
[17] Bommer, J., Martinez-Pereira, A.: The Effective Duration of Earthquake Strong Motion, Journal of Earthquake Engineering, Imperial College Press, Vol. 3, No. 2, pp. 127-172, 1999.

[18] Rathje, E., Abrahamson, N., Bray, J.: Simplified Frequency Content Estimates of Earthquake Ground Motions, Journal of Geotechnical and Geoenvironmental Engineering, Vol. 124, No. 2, pp. 150-159, 1998.
[19] Vamvatsikos, D., Cornell, A.: Incremental Dynamic Analysis, Earthquake Engineering and Structural Dynamics, Vol. 31, No. 3, pp. 491-514, 2002.

[20] Park, Y., Ang, A., Wen, Y.: Seismic Damage Analysis of Reinforced Concrete Buildings, Journal of Structural Engineering, Vol. 111, No. 4, pp. 740-757, 1985. 